\title{
Nephrotoxic Effects of Stevioside and Steviol in Rat Renal Cortical Slices
}

\author{
Chaivat Toskulkao, ${ }^{1, *}$ Wimon Deechakawan, ${ }^{2}$ Punya Temcharoen, ${ }^{3}$ \\ Dhuang BuddhasuKH, ${ }^{4}$ and Thirayudh GLINSUKON ${ }^{1, * *}$ \\ ${ }^{1}$ Department of Physiology, ${ }^{2}$ Graduate Program in Toxicology, and ${ }^{3}$ Department of \\ Pathobiology, Faculty of Science, Mahidol University, \\ Rama 6 Road, Bangkok 10400, Thailand \\ ${ }^{4}$ Department of Chemistry, Faculty of Science, Chiang Mai University, \\ Chiang Mai 50002, Thailand
}

(Received October 4, 1993)

\begin{abstract}
Summary Nephrotoxic effects of stevioside and steviol on $p$-aminohippurate $(\mathrm{PAH})$ accumulation in rat renal cortical tissue were demonstrated. Subcutaneous administration of stevioside $(1.5 \mathrm{~g} / \mathrm{kg}$ body weight) to rats for $9 \mathrm{~h}$ significantly $(p<0.001)$ decreased the ability of excised renal cortex slices to accumulate PAH in vitro by $63.4 \%$. Stevioside had no effect on lipid peroxidation in the plasma and renal cortical slices at $9 \mathrm{~h}$ after administration. Addition of either stevioside (6.25-100 $\mu \mathrm{M})$ or steviol $(1.56-100 \mu \mathrm{M})$ to the incubation medium inhibited PAH accumulation in the rat renal cortical slices after a 30-min incubation. This inhibitory effect was dose dependent, and was at its maximum at 25 $\mu \mathrm{M}$. Steviol was more potent than stevioside in inhibiting PAH uptake by renal cortical slices. Stevioside and steviol at a concentration of $100 \mu \mathrm{M}$ had no effect on lipid peroxidation in rat renal cortical slices incubated for $30 \mathrm{~min}$ in vitro. These results suggest that the nephrotoxic effects induced by stevioside and steviol in rats are not related to lipid peroxidation.
\end{abstract}

Key Words: stevioside, steviol, stevia, sweetener, nephrotoxicity, lipid peroxidation

Stevioside is a sweet component of the wild shrub Stevia rebaudiana, whose leaves have traditionally been used as a sweetener. The purified extract is a white, crystalline, odorless powder and is approximately 300 times sweeter than sucrose.

*To whom correspondence should be addressed.

**Present address: Department of Physiology, Faculty of Science, Rangsit University, Pathumthani 12000, Thailand. 
It is composed of steviol, a diterpenic carboxylic alcohol, and three glucose molecules $[1,2]$. The sweetening effect of stevioside has received worldwide attention. In Japan, stevia has been widely cultivated and used commercially as a sweetener since 1975. Stevioside offers advantages over other noncaloric sucrose substitutes in being heat-stable, somewhat resistant to acid hydrolysis, and nonfermentable [3]. Many researchers have demonstrated that stevioside may be used not only for sweetening purposes, but also for its physiologic and therapeutic effects [4]. It has also been shown to act as a contraceptive drug $[5,6]$, and to have cardiovascular [7] and metabolic [8] effects.

Available knowledge about the effects of stevioside on the kidney is inadequate. It has been found that stevioside can cause nephrotoxicity in both hamsters and rats $[9,10]$ and that steviol, its aglycone, can inhibit glucose production and oxygen uptake of rat renal tubules [11]. Stevioside is converted to steviol in vivo, and the converted substance is subsequently absorbed through the gastrointestinal wall [12]. PAH accumulation is a representative biochemical process that relies on the transport ability of renal cells and can be used for screening unknown chemicals for evaluation of their nephrotoxicity, and also for mechanistic investigation of chemically induced nephrotoxicity [13]. Therefore, this study was designed to investigate the nephrotoxic effects of stevioside and steviol on PAH accumulation in rat renal cortical tissue both in vivo and in vitro.

\section{MATERIALS AND METHODS}

Materials. Stevioside and steviol were kindly supplied by Dr. Dhuang Buddhasukh, Department of Chemistry, Faculty of Science, Chiang Mai University. Stevioside was extracted and purified from dried Stevia rebaudina leaves as described by Adduci et al. [14]. Steviol was obtained by oxidation of stevioside as described by Ogawa et al. [15]. Both were fine, white powders of more than $90 \%$ purity. All chemicals and solvents used throughout the investigation were analytical grade. Reagents for determination of protein, malondialdehyde (MDA), and PAH were purchased from Sigma Chemical Co., St. Louis, MO.

Animals. Male Wistar rats (200-250 g) supplied from the National Animal Center, Mahidol University, were housed in stainless steel cages in a room at approximately $25 \pm 2^{\circ} \mathrm{C}$ with relative humidity at about $65 \%$. The animals were fed regular rat chow (Gold Coins Co., Singapore) and water ad libitum. Prior to each experiment the rats were fasted overnight but allowed free access to water.

Effect of stevioside on PAH accumulation and lipid peroxidation in vivo. Groups of 8 fasted rats were subcutaneously injected with $1.5 \mathrm{~g} / \mathrm{kg}$ body weight stevioside ( $10 \%$ aqueous solution) or distilled water. Then the rats were housed in the stainless steel cages and were given food and water ad libitum. The animals were sacrificed at $9 \mathrm{~h}$ after stevioside administration, at which time the maximum nephrotoxic effect of stevioside is observed [10]. Blood was collected from the abdominal aorta for determination of lipid peroxide level according to the method 
of Ohkawa et al. [16]. Both kidneys were immediately removed and washed with ice-cold $0.9 \% \mathrm{NaCl}$ solution. The procedure for preparation of renal cortical slices was based on the method of Sugihara et al. [17]. All steps were performed on ice at $4^{\circ} \mathrm{C}$. Thin slices $(0.3-0.5 \mathrm{~mm})$ were prepared in $0.9 \% \mathrm{NaCl}$ solution freehand with a razor blade, and were continuously oxygenated with $100 \% \mathrm{O}_{2}$ throughout the experiment. The slices were pooled and immersed together in chilled $0.9 \%$ $\mathrm{NaCl}$ solution prior to use in the experiments.

Effect of stevioside and steviol on PAH accumulation in vitro. Groups of 10 fasted rats were sacrificed by decapitation and the renal cortical slices were prepared. The slices were pooled and divided into 4 groups. Group I and II renal slices were incubated in $10 \mathrm{ml}$ of incubation medium supplemented with distilled water and dimethylsulfoxide (DMSO), respectively. Group III slices were incubated in $10 \mathrm{ml}$ of medium with stevioside (10\%) at concentrations ranging from 6.25 $100 \mu \mathrm{M}$. Group IV slices were incubated in $10 \mathrm{ml}$ of medium with steviol $(1 \mathrm{mg} /$ $2.5 \mu 1 \mathrm{DMSO}$ ) at concentrations ranging from 1.56-100 $\mu \mathrm{M}$. After a 30-min incubation at $37^{\circ} \mathrm{C}, \mathrm{PAH}$ accumulation in the slices and incubation media were determined.

Effect of stevioside and steviol on renal lipid peroxide content. Groups of 10 fasted rats were sacrificed and the renal cortical slices were prepared [17], pooled, and also divided into 4 groups for incubation in medium containing distilled water, DMSO, stevioside, or steviol. The slices $(200 \mathrm{mg})$ were incubated with and without $100 \mu \mathrm{M}$ stevioside (10\%) or steviol ( $1 \mathrm{mg} / 2.5 \mu 1 \mathrm{DMSO})$ in $4 \mathrm{ml}$ of incubation medium containing $150 \mathrm{~mm} \mathrm{KCl}$ and $20 \mathrm{~mm}$ Tris- $\mathrm{HCl}$ buffer, $\mathrm{pH}$ 7.4. The incubation medium in each flask was oxygenated with $100 \% \mathrm{O}_{2}$, capped tightly, and slightly shaken in a metabolic shaker for $5 \mathrm{~min}$ before the experiment. At various time intervals (0-30 min) after incubation, the slices were removed, blotted, weighed, and homogenized in $1 \mathrm{ml}$ of the same medium at $4^{\circ} \mathrm{C}$ in a glass Potter-Elvehjem type homogenizer using a Teflon pestle (10 excursions at $80 \mathrm{rpm}$ ). The homogenate was then assayed for lipid peroxide [16] and protein content [18].

$P A H$ accumulation in renal cortical slices. The experimental procedure for measurement of PAH accumulation in the slices was based on a modification of the methods of Sugihara et al. [17] and Hannemann and Baumann [19]. Renal cortical slices $(150 \mathrm{mg}$ ) were incubated in $10 \mathrm{ml}$ of incubation medium containing $134 \mathrm{~mm} \mathrm{NaCl}, 5.9 \mathrm{mM} \mathrm{KCl}, 1.5 \mathrm{mM} \mathrm{CaCl}_{2}, 1.2 \mathrm{mM} \mathrm{MgCl}_{2}, 11.5 \mathrm{~mm}$ glucose, $5.8 \mathrm{~mm}$ Hepes buffer ( $\mathrm{pH} 7.4$ ), and $0.074 \mathrm{mM} \mathrm{PAH}$ at $37^{\circ} \mathrm{C}$. The incubation medium in each flask was oxygenated with $100 \% \mathrm{O}_{2}$, capped tightly, and slightly shaked in the metabolic shaker for $5 \mathrm{~min}$ before experiments. After a 30-min incubation with and without stevioside or steviol, the slices were removed, blotted, weighed, and homogenized in $10 \mathrm{ml}$ of $3 \%$ trichloroacetic acid. An aliquot of $1 \mathrm{ml}$ of incubation medium was treated with $9 \mathrm{ml}$ of $3 \%$ TCA. PAH concentrations in the slices and medium were determined by the method of Bratton and Marshall [20]. 


\section{RESULTS}

At $9 \mathrm{~h}$ after subcutaneous injection of rats with stevioside $(1.5 \mathrm{~g} / \mathrm{kg}$ body weight), renal cortical slices were prepared and then incubated in the medium with $0.074 \mathrm{~mm} \mathrm{PAH}$ at $37^{\circ} \mathrm{C}$ for $30 \mathrm{~min}$. In control rats, final PAH concentrations in the medium and in the slices were $13.7 \pm 0.3 \mu \mathrm{g} / \mathrm{ml}$ and $77.3 \pm 1.9 \mu \mathrm{g} / \mathrm{g}$ tissue, respectively. PAH accumulation as slice-to-medium (S/M) ratio was $5.6 \pm 0.2$. Final PAH concentrations in medium and slices from stevioside-treated rats were $14.8 \pm$ $1.7 \mu \mathrm{g} / \mathrm{ml}$ and $28.3 \pm 4.1 \mu \mathrm{g} / \mathrm{g}$ tissue, respectively, giving an $\mathrm{S} / \mathrm{M}$ ratio of $1.9 \pm 0.3$. Thus PAH transport in the slices was inhibited by stevioside by $63.4 \%$. The $\mathrm{S} / \mathrm{M}$ ratio in rats treated with stevioside was significantly reduced by $65.9 \%$ (from $5.6 \pm$ 0.2 to $1.9 \pm 0.3, p<0.001)$.

Table 1. Effect of stevioside on PAH accumulation in rat renal cortical slices in vitro.

\begin{tabular}{cccccc}
\hline $\begin{array}{c}\text { Stevioside } \\
(\mu \mathrm{M})\end{array}$ & $\begin{array}{c}\text { No. of } \\
\text { slices }^{\mathrm{a}}\end{array}$ & $\begin{array}{c}\text { Medium } \\
(\mu \mathrm{g} / \mathrm{ml})\end{array}$ & $\begin{array}{c}\text { Slices } \\
(\mu \mathrm{g} / \mathrm{g})\end{array}$ & $\begin{array}{c}\mathrm{S} / \mathrm{M} \\
\text { ratio }^{\mathrm{b}}\end{array}$ & $\begin{array}{c}\text { Inhibition }^{\mathrm{c}} \\
(\%)\end{array}$ \\
\hline 0 & 20 & $13.9 \pm 0.3$ & $77.7 \pm 2.2$ & $5.6 \pm 0.3$ & - \\
6.25 & 6 & $14.0 \pm 0.3$ & $70.2 \pm 2.8$ & $5.0 \pm 0.2^{*}$ & $11.6 \pm 2.5$ \\
12.5 & 6 & $14.1 \pm 0.2$ & $61.9 \pm 2.6$ & $4.4 \pm 0.3^{* *}$ & $21.4 \pm 3.0$ \\
25 & 6 & $14.4 \pm 0.3$ & $53.6 \pm 2.5$ & $3.7 \pm 0.3^{* * *}$ & $33.3 \pm 4.2$ \\
50 & 6 & $14.5 \pm 0.2$ & $52.1 \pm 1.8$ & $3.6 \pm 0.2^{* * *}$ & $35.1 \pm 2.7$ \\
100 & 6 & $14.4 \pm 0.2$ & $51.2 \pm 2.0$ & $3.6 \pm 0.2^{* * *}$ & $36.4 \pm 2.4$ \\
\hline
\end{tabular}

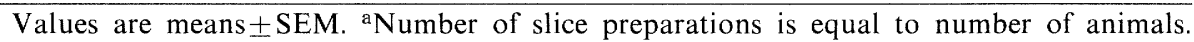
${ }^{\mathrm{b}}$ Final PAH concentration is expressed as slice-to-medium (S/M) concentration ratio. S/M ratio is compared between the control (water) and stevioside-treated groups. Significant values (Student's $t$-test) are indicated by asterisks: ${ }^{*} p<0.05,{ }^{* *} p<0.01,{ }^{* * *} p<0.001$. ${ }^{\mathrm{c}}$ The degree of inhibition of PAH accumulation is derived from a comparison of the final PAH concentrations in slices from control (water) and stevioside-treated groups.

Table 2. Effect of steviol on PAH accumulation in rat renal cortical slices in vitro.

\begin{tabular}{|c|c|c|c|c|c|}
\hline \multirow[b]{2}{*}{$\begin{array}{c}\text { Steviol } \\
(\mu \mathrm{M})\end{array}$} & \multirow[b]{2}{*}{$\begin{array}{l}\text { No. of } \\
\text { slices }^{\text {a }}\end{array}$} & \multicolumn{3}{|c|}{ Final PAH concentration } & \multirow{2}{*}{$\begin{array}{c}\text { Inhibition } \\
(\%)\end{array}$} \\
\hline & & $\begin{array}{l}\text { Medium } \\
(\mu \mathrm{g} / \mathrm{ml})\end{array}$ & $\begin{array}{l}\text { Slices } \\
(\mu \mathrm{g} / \mathrm{g})\end{array}$ & $\begin{array}{c}\mathrm{S} / \mathrm{M} \\
\text { ratio }^{\mathrm{b}}\end{array}$ & \\
\hline 0 & 21 & $13.9 \pm 0.3$ & $78.9 \pm 2.2$ & $5.6 \pm 0.2$ & - \\
\hline 1.56 & 6 & $14.2 \pm 0.3$ & $58.4 \pm 2.3$ & $4.1 \pm 0.4^{* *}$ & $26.2 \pm 3.3$ \\
\hline 3.13 & 6 & $14.8 \pm 0.2$ & $47.5 \pm 2.8$ & $3.2 \pm 0.3^{* * *}$ & $39.8 \pm 3.6$ \\
\hline 6.25 & 6 & $14.9 \pm 0.2$ & $40.0 \pm 2.2$ & $2.7 \pm 0.2^{* * *}$ & $49.3 \pm 2.7$ \\
\hline 12.5 & 6 & $15.1 \pm 0.2$ & $30.6 \pm 2.4$ & $2.0 \pm 0.2^{* * *}$ & $61.3 \pm 3.0$ \\
\hline 25 & 6 & $15.3 \pm 0.2$ & $26.0 \pm 1.6$ & $1.7 \pm 0.2^{* * *}$ & $67.1 \pm 1.9$ \\
\hline 50 & 6 & $15.9 \pm 0.2$ & $18.8 \pm 0.8$ & $1.2 \pm 0.1^{* * *}$ & $76.5 \pm 1.1$ \\
\hline 100 & 6 & $15.9 \pm 0.1$ & $19.2 \pm 0.8$ & $1.2 \pm 0.1 * * *$ & $76.2 \pm 1.4$ \\
\hline
\end{tabular}

Values are means \pm SEM.

See legend of Table 1 for meaning of foot notes. 
Table 3. Time-course effects of stevioside on lipid peroxidation in rat renal cortical slices in vitro.

\begin{tabular}{cccc}
\hline $\begin{array}{c}\text { Time of incubation } \\
(\mathrm{min})\end{array}$ & $\begin{array}{c}\text { Stevioside } \\
(\mu \mathrm{M})\end{array}$ & No. of slices $^{\mathrm{a}}$ & $\begin{array}{c}\text { Lipid peroxidation } \\
(\text { nmol MDA/mg protein) }\end{array}$ \\
\hline 0 & 0 & 9 & $0.54 \pm 0.05$ \\
5 & 0 & 9 & $0.96 \pm 0.04$ \\
& 100 & 9 & $0.96 \pm 0.05(\mathrm{NS})$ \\
10 & 0 & 9 & $0.93 \pm 0.05$ \\
& 100 & 9 & $0.95 \pm 0.05(\mathrm{NS})$ \\
20 & 0 & 9 & $0.87 \pm 0.05$ \\
& 100 & 9 & $0.89 \pm 0.04(\mathrm{NS})$ \\
30 & 0 & 9 & $0.87 \pm 0.05$ \\
& 100 & 9 & $0.88 \pm 0.05(\mathrm{NS})$ \\
\hline
\end{tabular}

${ }^{a}$ Number of slice preparations is equal to number of animals. Values are means \pm SEM. (NS), no significant difference.

Table 4. Time-course effects of steviol on lipid peroxidation in rat renal cortical slices in vitro.

\begin{tabular}{cccc}
\hline $\begin{array}{c}\text { Time of incubation } \\
(\mathrm{min})\end{array}$ & $\begin{array}{c}\text { Steviol } \\
(\mu \mathrm{M})\end{array}$ & No. of slices & $\begin{array}{c}\text { Lipid peroxidation } \\
(\text { nmol MDA/mg protein) }\end{array}$ \\
\hline 0 & 0 & 9 & $0.52 \pm 0.05$ \\
5 & 0 & 9 & $0.49 \pm 0.04$ \\
& 100 & 9 & $0.47 \pm 0.03(\mathrm{NS})$ \\
10 & 0 & 9 & $0.49 \pm 0.04$ \\
& 100 & 9 & $0.48 \pm 0.02(\mathrm{NS})$ \\
20 & 0 & 9 & $0.57 \pm 0.04$ \\
& 100 & 9 & $0.56 \pm 0.01(\mathrm{NS})$ \\
& 0 & 9 & $0.78 \pm 0.03$ \\
& 100 & 9 & $0.82 \pm 0.03(\mathrm{NS})$ \\
\hline
\end{tabular}

${ }^{a}$ Number of slices preparations is equal to number of animals. Values are means \pm SEM.

(NS), no significant difference.

Plasma lipid peroxidation rose slightly from $0.086 \pm 0.003 \mathrm{nmol} \mathrm{MDA} / \mathrm{mg}$ protein in control rats to $0.089 \pm 0.005 \mathrm{nmol} \mathrm{MDA} / \mathrm{mg}$ protein in steviosidetreated rats at $9 \mathrm{~h}$ after administration. Lipid peroxidation in renal cortex was changed from $0.66 \pm 0.10 \mathrm{nmol} \mathrm{MDA} / \mathrm{mg}$ protein in control rats to $0.72 \pm 0.12$ $\mathrm{nmol} \mathrm{MDA} / \mathrm{mg}$ protein in stevioside-treated rats during the same period of time. However, in neither case was the difference statistically different.

Table 1 shows the dose-response effects of stevioside on PAH accumulation in rat renal cortical slices in vitro. $\mathrm{PAH}$ accumulation as slice to medium $(\mathrm{S} / \mathrm{M})$ ratio was significantly reduced at stevioside concentrations of $6.25 \mu \mathrm{M}$ and above, and the degree of reduction of the S/M ratio was dependent on the stevioside concentration. In stevioside-treated renal cortical slices $(6.25-100 \mu \mathrm{M})$, PAH accumulation in the slices was inhibited when compared with that of the controls by 11.6 to $36.4 \%$. Maximum inhibition of PAH accumulation in the slices was observed with $50 \mu \mathrm{M}$ stevioside treatment. 
Dose-response effects of steviol on PAH accumulation in rat renal cortical slices in vitro are summarized in Table 2. PAH accumulation as slice-to-medium $(\mathrm{S} / \mathrm{M})$ ratio was significantly reduced at all concentrations of steviol; and the degree of reduction was dependent on the steviol concentration, ranging from 26.2 to $76.5 \%$. Maximum inhibition of PAH accumulation in the slices was observed with $50 \mu \mathrm{M}$ steviol treatment.

Effects of stevioside and steviol on lipid peroxidation in rat renal cortical slices are summarized in Tables 3 and 4 . The concentration of $100 \mu \mathrm{M}$ stevioside or steviol used in this experiment had the maximum inhibitory effect on PAH accumulation (Tables 1 and 2). The lipid peroxide content of stevioside-treated slices was slightly increased but was not significantly different from that of the control (water) slices at 10, 20, and $30 \mathrm{~min}$ of incubation (Table 3). In stevioltreated slices (Table 4), the lipid peroxide content slightly decreased after 5, 10, and $20 \mathrm{~min}$ of incubation compared with that of the control (DMSO) slices. At 30 min of incubation, however, the content of steviol-treated slices was slightly, but not significantly, increased over that of the control (DMSO) slices.

\section{DISCUSSION}

Acute renal failure produced by stevioside has been studied in terms of the changes in plasma and urinary biochemical parameters and pathological changes in renal proximal tubular cells $[9,10]$. Another biochemical process was assessed in the present study to see whether stevioside could inhibit PAH transport in renal cortical tissue either from the kidney of rats treated with stevioside, or with stevioside present in the medium.

In the present study, the time of $9 \mathrm{~h}$ after subcutaneous injection of stevioside selected for determination of $\mathrm{PAH}$ accumulation in renal cortical slices relates to the time of maximum levels of blood urea nitrogen and plasma creatinine $[9,10]$ that are routinely useful for toxicological evaluation of the kidney. The 30 -min incubation time for study of PAH accumulation in rat renal cortical slices is sufficient for PAH to reach equilibrium $[13,21]$. We found that prior stevioside treatment in vivo significantly reduced PAH accumulation in the renal cortical slices of rats. However, stevioside and steviol administered in vitro also inhibited PAH accumulation in rat renal slices (Tables 1 and 2). Steviol was more potent than stevioside. At the same concentration $(6.25 \mu \mathrm{M})$, steviol had nearly four times the ability to inhibit PAH accumulation.

The mechanism of inhibition of PAH transport in proximal tubular cells by stevioside in vivo is not yet known. It is possible that stevioside is hydrolyzed to steviol and/or other active metabolites by microsomal enzymes in the proximal convoluted tubule cells and hepatocytes. These metabolic products may exert their action on organelles, especially mitochondria of the cells of the proximal convoluted tubules [10]. Steviol, isosteviol, and glucosilsteviol are capable of inhibiting oxidative phosphorylation in isolated rat liver mitochondria [11,22] and can also 
inhibit glucose production and oxygen uptake in rat renal tubules [11]. Therefore, it is quite possible that steviol or other active metabolites cause a decrease in energy supply for PAH transport in the proximal convoluted tubules of steviosidetreated rats.

Considering the in vitro inhibitory effects of stevioside and steviol on PAH accumulation of rat renal cortical slices, one possible mechanism is that stevioside as well as steviol may inhibit renal cell metabolism. Stevioside, an inhibitor of oxidative phosphorylation in isolated mitochondria, does not affect energy metabolism in intact cells because it cannot freely diffuse across biological membranes [22]. In isolated renal tubules, stevioside has no effect on oxygen uptake and gluconeogenesis [11]. This possibility seems more plausible as stevioside, an oligosaccharide, cannot freely penetrate the cell membrane. Thus, the site of action of stevioside is located on the outside of the cell. In our study, stevioside caused an inhibition of PAH accumulation in rat renal cortical slices in vitro. It is possible that stevioside acts directly on one of the processes of the three active transport systems: $\mathrm{Na}^{+}, \mathrm{K}^{+}$-ATPase system, cotransport system of dicarboxylatesodium ions, or the countertransport system of PAH with dicarboxylates at the basolateral membrane of proximal tubular cells in the cortical slices, which causes the accumulation of PAH in the cells [23]. In steviol-containing medium, steviol may somehow act in a manner similar to stevioside. Steviol is more potent than stevioside in several experimental systems including isolated rat liver mitochondria [22], isolated renal tubules [11], rabbit reticulocytes [24] and isolated perfused rat liver [25]. Steviol had a higher inhibitory effect on PAH accumulation in rat renal cortical slices than stevioside. In these cases, it is likely that steviol, which is lipophilic, may be transported across the basolateral membrane into the renal slices and affect the organelles in the cell, especially the mitochondria.

Several lines of evidence suggest that lipid peroxidation is one mechanism involved in renal toxicity $[17,19,26,27]$. This may involve oxidative degradation of membrane lipid resulting in altered membrane permeability and transport characteristics, as well as peroxidation-induced damage and dysfunction of nearby proteins and organelles $[28,29]$. In this study, we examined the changes in lipid peroxide levels in plasma and renal tissue of rats treated with stevioside in vivo and the effects of stevioside and steviol on lipid peroxide levels in rat renal cortical slices in vitro, and found that stevioside induced no change in lipid peroxidation in either plasma or renal cortex, despite a reduction of $\mathrm{PAH}$ accumulation in rat renal cortical slices. Similarly, lipid peroxidation in rat renal cortical slices was unaffected by either stevioside or steviol after various time intervals in vitro. It is thus likely that stevioside and steviol have no effect on lipid peroxidation in rat renal cortical slices despite the reduced PAH accumulation.

In conclusion, stevioside and steviol do not act on the renal cells via lipid peroxidation to induce PAH accumulation in rat renal cortical slices. Stevioside and steviol may act directly on the transport system of PAH at the basolateral membrane of the proximal tubules cells of the kidney. Steviol may permeate the 
renal cells and affect their organelles, especially the mitochondria.

This work was supported by grants from the International Foundation for Science (IFS Grant \#F/1690-1) and Mahidol University. Stevia samples were obtained from the Research Institute of Pharmacognosy under the Royal Scheme, Chiang Mai. The authors would like to thank Ms. Kosoom Vongthai for her typing.

\section{REFERENCES}

1. Wood, H.B., Jr., Allerton, R., Diehi, H.W., and Fletcher, H.G. (1955): Stevioside. I: The structure of glucose moieties. J. Org. Chem., 20, 875-879.

2. Mosettig, E., and Nes, W.R. (1955): Stevioside. II: The structure of the aglycone. J. Org. Chem., 20, 884-888.

3. Kinghorn, A.D., and Soejarto, D.D. (1991): Stevioside, in Alternative Sweeteners, Vol. 2, ed. by O'Brien Nabors, L. and Gelardi, R.C., Dekker, New York, pp. 157-171.

4. Sakaguschi, M., and Kan, P. (1982): As pesquisas japonesas com Stevia rebaudiana (Bert.) Bertoni e o esteviosideo. Ciênc. Cult., 34, 235-248.

5. Planas, G.M., and Kue, J. (1968): Contraceptive properties of Stevia rebaudiana. Science, 162, 1007.

6. Portella Nunes, B.A., and Pereira, N.A. (1988): Efeito da Caa-heê (Stevia rebaudiana) (Bert) (Bertoni) sobre a fertilidade de amimais experientias. Rev. Bras. Farm., 69, 46-50.

7. Boeckh, E.M.A., and Humboldt, G. (1981): Efeitos cardiocirculatorios do extrato aquoso t otal em individuos normais e do esteviosideo em ratos. Ciênc. Cult., 32, 208-210.

8. Curi, R., Alvarez, M., Bazotte, R.B., Botion, L.M., Godoy, J.L., and Bracht, A. (1986): Effect of Stevia rebaudiana on glucose tolerance in normal adult man. Braz. J. Med. Biol. Res., 19, 771-774.

9. Panichkul, T., Glinsukon, T., Buddhasukh, D., Cheuychit, P., and Pimolsri, U. (1988): The plasma levels of urea nitrogen, creatinine and uric acid and urine volume in rats and hamsters treated with stevioside. Thai. J. Toxicol, 4, 47-52.

10. Toskulkao, C., Deechakawan, W., Leardkamolkarn, V., Buddhasukh, D., and Glinsukon, T. (1994): Stevioside nephrotoxicity and its relationship to urinary enzymes excretion in the rat. Phytother. Res. (in press).

11. Yamamoto, N.S., Kelmer Bracht, A.M., Ishii, E.L., Kemmelmier, F.S., Alvarez, M., and Bracht, A. (1985): Effect of steviol and its structural analogues on glucose production and oxygen uptake in rat renal tubules. Experientia, 41, 55-57.

12. Wingard, R.E., Jr., Brown, J.P., Enderlin, F.E., Dale, J.A., Hale, R.L., and Seitz, E.T. (1980): Intestinal degradation and absorption of the glycosidic sweeteners stevioside and rebaudioside A. Experientia, 36, 519-520.

13. Kameyama, Y., Okazaki, N., Nakagawa, M., Koshida, H., Nakamura, M., and Gemba, M. (1990): Nephrotoxicity of a new platinum compound, 254-S, evaluated with rat kidney cortical slices. Toxicol. Lett., 52, 15-24.

14. Adduci, J., Buddhasukh, D., and Ternai, B. (1987): Improved isolation and purification of stevioside. J. Sci. Soc. Thail., 12, 179-183.

15. Ogawa, T., Nozaki, M., and Matsui, M. (1980): Total synthesis of stevioside. Tetrahedron, 36, 2641-2648.

16. Ohkawa, H., Ohishi, N., and Yagi, K. (1979): Assay for lipid peroxides in animal tissues by thiobarbituric acid reaction. Anal. Biochem., 95, 351-358.

17. Sugihara, K., Nakano, S., and Gemba, M. (1987): Effect of cisplatin on in vitro production of lipid peroxides in rat kidney cortex. Jpn. J. Pharmacol, 44, 71-76.

18. Lowry, O.H., Rosebrough, N.J., Farr, A.L., and Randall, R.J. (1951): Protein measurement with the folin-phenol reagent. J. Biol. Chem., 193, 265-275.

19. Hannemann, J., and Baumann, K. (1988): Cisplatin-induced lipid peroxidation and decrease 
of gluconeogenesis in rat kidney cortex: Different effects of antioxidants and radical scavengers. Toxicology, 51, 119-132.

20. Bratton, A.C., and Marshall, E.K. (1939): A new coupling component for sulfanilamide determination. J. Biol. Chem., 128, 537-550.

21. Gemba, M., Tachibana, A., Sugihara, K., Hori, M., and Nakajima, M. (1985): Inhibitory effect of lithium on $p$-aminohippurate transport in rat kidney cortex in vitro. Renal Physiol. Basel, 8, 179-188.

22. Bracht, A.K., Alvarez, M., and Bracht, A. (1985): Effects of Stevia rebaudiana natural products on rat liver mitochondria. Biochem. Pharmacol., 34, 873-882.

23. Shimada, H., Moewes, B., and Burckhardt, G. (1987): Indirect coupling to $\mathrm{Na}^{+}$of $p$ aminohippuric acid uptake into rat renal basolateral membrane vesicles. Am. J. Physiol., 253, F795-F801.

24. Bracht, A.K., Kemmelmier, F.S., Ishii, E.L., Alvarez, M., and Bracht, A. (1985): Effect of Stevia rebaudiana natural products on cellular and subcellular metabolism. Archos Biol. Technol., 28, 431-455.

25. Ishii, E.L., and Bracht, A. (1986): Stevioside, the sweet glycoside of Stevia rebaudiana, inhibits the action of atractyloside in the isolated rat liver. Res. Commun. Chem. Pathol. Pharmacol, 53, 79-91.

26. Kameyama, Y., and Gemba, M. (1991): The iron chelator deferoxamine prevent cisplatininduced lipid peroxidation in rat kidney cortical slices. Jpn. J. Pharmacol., 57, 259-262.

27. Sadzuka, Y., Shoji, T., and Takino, Y. (1991): Change of lipid peroxide levels in rat tissues after cisplatin administration. Toxicol. Lett., 57, 159-166.

28. Weinberg, J.M. (1988): The cellular basis of nephrotoxicity, in Diseases of the Kidney, Vol. 2 (4th ed.), ed. by Schrier, R.W. and Gottschalk, C.W., Little, Brown and Co., Boston, pp. $1137-1195$.

29. Hoffsten, P.E., Hunter, F.E., Jr., Gebicki, J.M., and Weinstein, J. (1962): Formation of "Lipid peroxide" under conditions which lead to swelling and lysis of rat liver mitochondria. Biochem. Biophys. Res. Commun., 7, 276-280. 